\title{
Genetic Basis of Human Complement C4A Deficiency Detection of a Point Mutation Leading to Nonexpression
}

\author{
Giovanna Barba, Christian Rittner, and Peter M. Schneider \\ Institute for Legal Medicine, Johannes Gutenberg University, D-6500 Mainz, Germany
}

\begin{abstract}
The fourth component of the human complement system (C4) is coded for by two genes, $\mathrm{C} 4 \mathrm{~A}$ and $\mathrm{C4B}$, located within the MHC. Null alleles of $\mathrm{C4}(\mathrm{C4Q0})$ are defined by the absence of $\mathrm{C} 4$ protein in plasma. These null alleles are due either to large gene deletions or to nonexpression of the respective genes. In a previous study, evidence was obtained for nonexpressed defective genes at the $\mathrm{C4A}$ locus, and for gene conversion at the $\mathrm{C4B}$ locus. To further characterize the molecular basis of these nonexpressed C4A genes, we selected nine pairs of PCR primers from flanking genomic intron sequences to amplify all 41 exons from individuals with a defective $\mathrm{C} 4 \mathrm{~A}$ gene. The amplified products were subjected to single-stranded conformation polymorphism (SSCP) analysis to detect possible mutations. PCR products exhibiting a variation in the SSCP pattern were sequenced directly. In 10 of 12 individuals studied, we detected a 2-bp insertion in exon 29 leading to nonexpression due to the creation of a termination codon, which was observed in linkage to the haplotype HLA-B60-DR6 in seven cases. In one of the other two individuals without this mutation, evidence was obtained for gene conversion to the $\mathrm{C4B}$ isotype. The genetic basis of $\mathrm{C} 4 \mathrm{~A}$ nonexpression in the second individual is not yet known and will be subject to further analysis. (J. Clin. Invest. 1993. 91:1681-1686.) Key words: genetic deficiency • complement system • insertional mutation • single-stranded conformation polymorphism • major histocompatibility complex
\end{abstract}

\section{Introduction}

The fourth component of the human complement system $(\mathrm{C} 4)^{1}$ is coded for by two genes, $\mathrm{C} 4 \mathrm{~A}$ and $\mathrm{C} 4 \mathrm{~B}$, located within the MHC class III region on the short arm of chromosome 6 (1). The two C4 isotypes differ in their amino acid sequences by $<1 \%$. The two $\mathrm{C} 4$ genes are tandemly arranged together with two genes for the cytochrome $\mathrm{P}_{450}$ steroid 21-hydroxylase (CYP21A and B), each located 3' to the C4A and C4B genes, respectively $(2,3)$. The $\mathrm{C} 4 \mathrm{~A}$ gene is usually $\sim 22 \mathrm{~kb}$ long,

Address correspondence to Dr. Peter M. Schneider, Institut für Rechtsmedizin, Am Pulverturm 3, D-6500 Mainz, FRG.

Received for publication 13 August 1992 and in revised form 30 November 1992.

1. Abbreviations used in this paper: $\mathrm{C} 2$ and $\mathrm{C} 4$, second and fourth components of complement; $\mathrm{C} 4 \mathrm{~A}$ and $\mathrm{C} 4 \mathrm{~B}$, isotypes $\mathrm{A}$ and $\mathrm{B}$ of the fourth component of complement; $\mathrm{C} 4 \mathrm{Q} 0, \mathrm{C} 4$ null allele; SSCP, singlestranded conformation polymorphism.

J. Clin. Invest.

(C) The American Society for Clinical Investigation, Inc.

0021-9738/93/04/1681/06 $\$ 2.00$

Volume 91, April 1993, 1681-1686 whereas the C4B gene is polymorphic in size with either 22 or $16 \mathrm{~kb}$. This size variation is due to the presence of a 7-kb intron located $\sim 2.5 \mathrm{~kb}$ from the 5 ' end of the $\mathrm{C} 4$ genes $(4,5)$.

At the protein level $\mathrm{C} 4$ is highly polymorphic, with $>40$ variants including null alleles (C4Q0) at both loci (6). Null alleles are defined by the absence of $\mathrm{C} 4$ protein in plasma and are present in the normal population at frequencies of $0.1-0.3$ (7). Complete deficiency of $\mathrm{C} 4$ is a rare event and is correlated with severe immune complex disease (8). Partial deficiency of one of the two isotypes (C4A or C4B) is more common and is also associated with an increased susceptibility to autoimmune or immune complex disease (e.g., in patients with systemic lupus erythematosus $[9,10]$, subacute sclerosing panencephalitis [11], or primary biliary cirrhosis [12]).

Genetic variation is also evident at the genomic level, as demonstrated by the detection of gene deletions and duplications. C4 null alleles are due either to large deletions comprising an entire $\mathrm{C} 4$ gene and the flanking 21-hydroxylase gene, or to nonexpression of the respective gene $(13,14)$. In a previous study on the molecular basis of $\mathrm{C} 4$ null alleles, evidence was obtained for defective genes at the $\mathrm{C} 4 \mathrm{~A}$ locus, and for gene conversion at the $\mathrm{C} 4 \mathrm{~B}$ locus as demonstrated by the presence of C4A-specific sequences (15).

To further characterize the molecular basis of the defective C4A genes, we developed a strategy based on PCR amplification and genomic DNA sequence analysis. We selected nine pairs of primers from the published C4A genomic sequence (5) to amplify all 41 exons from individuals homozygous for C4AQ0. All individuals studied carried a nonexpressed C4A gene on one haplotype and a C4A gene deletion on the other haplotype. The amplified DNA fragments were subjected to single-stranded conformation polymorphism (SSCP) analysis to detect possible mutations. Finally, direct DNA sequencing of the PCR product exhibiting a variation in the SSCP pattern was used to define the type of mutation. Using this approach we detected a 2-bp insertion in exon 29 leading to nonexpression. However, this mutation was only found in 10 of 12 haplotypes studied.

\section{Methods}

Selection of individuals and genetic typing. 12 individuals with homozygous C4A deficiency were selected. All individuals had been haplotyped for MHC class I, II, and III gene products in family studies by our laboratory as well as by other collaborating laboratories $(6,15,16)$ according to the following methods: HLA-A, -B, and -C, and -DR antigens were assigned by the microlymphocytotoxicity assay (17); C4 typing was carried out by high voltage agarose gel electrophoresis in a discontinuous buffer system after desialation of the samples with neuraminidase, followed by immunofixation or hemolytic overlay (18); $\mathrm{C} 4 \mathrm{Q} 0$ alleles were confirmed by $\mathrm{C} 4 \alpha$-chain typing using SDS-PAGE (19); restriction fragment length polymorphism analysis was carried out by Southern blot with TaqI-digested genomic DNA and hybridization to C4- and CYP21-specific probes as described (14). 
Table I. Sequence of Primer Pairs Used

for Exon-specific PCR

Amplification

\begin{tabular}{rlcc}
\hline $\begin{array}{c}\text { Primer } \\
\text { pairs }\end{array}$ & \multicolumn{1}{c}{ Sequence (5'-3') } & $\begin{array}{c}\text { C4 exons } \\
\text { amplified }\end{array}$ & Size \\
\hline & & & $b p$ \\
$5^{\prime}$ & CCACAACTCTGGGCCTGAGGCCA & $1-4$ & 1,323 \\
2 & CACAGGCAGAGGTCACATCAGTG & & \\
3 & GACCTCTGCCTGTGACCTACTTC & $5-9$ & 1,228 \\
4 & GTTAGCTCAGAGGTCAGAGGCAA & & \\
5 & TCCCTCTCTTCTTGGGCTCTGTC & $10-13$ & 1,129 \\
6 & TCGGCACAAGTGCCATCTCTCCT & & \\
7 & GAAGCTCTCCCACTCTGACCGCC & $14-17$ & 1,324 \\
8 & CAAGCGCCGCCACCTGTGCCCTA & & \\
9 & GCGCTTGGAAAGGCAGAACGGTC & $18-22$ & 1,386 \\
10 & ACTTAGGAAACCAATGGCTGGAG & & \\
11 & ACAGCAGGACAGGCTGCCAACTT & $23-28$ & 1,569 \\
12 & CCTCAGGCTCAGTGCCAGAGCGC & & \\
13 & CTTCCTGTTTACTTGTGGTCTCC & $29-31$ & 1,021 \\
14 & ACCCTCTCCTCCACCAGTGCCTG & & \\
15 & CCTCACATGTCCCACGTCCTCTC & $32-35$ & 827 \\
16 & ATCGAGTCCCTTCCTGCCTCATC & & \\
17 & AACAGGCCAAGGAAACCCAGTAC & $36-41$ & 1,735 \\
18 & GCAACACACACTGACACTTCGCT & & \\
\hline \multicolumn{7}{c}{} & & \\
\hline
\end{tabular}

PCR amplification. Nine pairs of oligonucleotide primers were chosen according to the published C4A genomic sequence from flanking intron sequences (5) as shown in Table $I$ and Fig. 1. With these primers all 41 exons of both $\mathrm{C} 4 \mathrm{~A}$ and $\mathrm{C} 4 \mathrm{~B}$ genes can be amplified. The PCR was performed in a thermocycler (Perkin-Elmer Corp., Norwalk, CT) with $100 \mathrm{ng}$ of genomic DNA, 25 pmol of each primer, $200 \mu \mathrm{M}$ dNTP, and 2 U Taq polymerase (Boehringer, Mannheim, FRG) using a "touchdown" protocol (20). The first 10 cycles were carried out at decreasing annealing temperatures in $1^{\circ} \mathrm{C}$ steps for two cycles each from 69 to $64^{\circ} \mathrm{C}$, followed by 20 cycles using the following conditions: $1 \min 94^{\circ} \mathrm{C} ; 2 \min 64^{\circ} \mathrm{C} ; 5 \min 72^{\circ} \mathrm{C}$. For primers $3 / 4$, a different touchdown program was carried out beginning with 12 cycles from 64 to $58^{\circ} \mathrm{C}$. Isotype-specific PCR was performed to amplify only the $\mathrm{C} 4 \mathrm{~A}$ allele using a $\mathrm{C} 4 \mathrm{~A}$-specific primer located in the $\mathrm{C} 4 \mathrm{~d}$ region and including the isotype-specific Chido-4 sequence as well as a second primer close to the possible mutation site: A-down, 5'-GACCCCTGTCCAGTGTTAGAC-3'; 13N, 5'-TTTCAATCCACAGGGCTGGGGCC-3' using a touchdown protocol from 67 to $62^{\circ} \mathrm{C}$.

SSCP analysis. PCR products were purified by adsorption to glass milk (Geneclean; BIO 101, La Jolla, CA) and digested with appropriate restriction enzymes to obtain small fragments with a size range between 700 and $50 \mathrm{bp}$. The samples were denatured with formamide by heating at $80^{\circ} \mathrm{C}$ for 3 min and kept on ice until loading. The mixture was separated either in a 0.75 -mm-thick MDE gel in $0.6 \times$ TBE buffer (AT Biochem, Malvern, PA) or in a standard polyacrylamide gel ( $5 \%$ total acrylamide, $1 \%$ crosslinker, $5 \%$ glycerol) polymerized on GelBond PAG film (Pharmacia LKB, Freiburg, FRG) at room temperature, applying $150 \mathrm{~V}$ and $5 \mathrm{~mA}$ for $2.5-20 \mathrm{~h}(21,22)$. Using these conditions, single-stranded DNA as well as heteroduplex fragments can be analyzed. The DNA was visualized by silver staining as described with minor modifications (23).

Detection of C4 isotype-specific sequences. Restriction fragment analysis of PCR products was carried out as published by Braun et al. (15). Briefly, the amplified DNA using PCR primers L3/L4 was purified by absorption to glass milk (see above) and digested with $2 \mathrm{U} \mathrm{Nla}$ IV (New England Biolabs, Schwalbach, FRG). The digested DNA was electrophoresed in a $1.5 \%$ agarose gel and visualized by ethidiumbromide staining.

Genomic DNA sequencing. For direct sequencing of PCR-amplified products, the amplified DNA fragments were purified by adsorption to glass milk (see above). The sequencing reaction was carried out on double-stranded DNA using the $T_{7}$ Sequencing Kit (Pharmacia LKB) and $\alpha-\left[{ }^{35} \mathrm{~S}\right] \mathrm{dATP}$ (DuPont NEN, Dreiech, FRG). Isotype-specific PCR fragments were sequenced by cycle sequencing with Taq DNA polymerase using the "fmol" DNA sequencing system (Promega Corp., Madison, WI).

\section{Results}

5 of the 12 individuals with homozygous C4A deficiency and one nonexpressed $\mathrm{C} 4 \mathrm{~A}$ gene selected for this study had been examined in a previous study for the presence of defective $\mathrm{C} 4 \mathrm{~A}$ genes using PCR amplification and subsequent restriction fragment analysis (15). The other seven individuals were selected from a C4 reference typing workshop (6) and from a recent disease association study (16). In these two studies, C4 typing had been carried out at the protein and DNA level in addition to HLA typing to establish complete MHC haplotypes. These seven samples were tested as described above for the presence of nonexpressed $\mathrm{C} 4 \mathrm{~A}$ genes using restriction analysis with the enzyme Nla IV, which detects the isotype-specific Chido -4/ +4 site of the $C 4 d$ region (amino acids $1101-1106$ located in exon 26$)(24,25$; see also Fig. 1$)$. In six of these samples, a defective C4A gene was detected (not shown), whereas in one sample (typed C4AQ0,Q0,B1,2), only the C4B-specific sequence (i.e., Chido +4 ) was found, as indicated by the absence of the Nla IV restriction site (Fig. 2 ). Thus, the C4A deficiency can be explained for this gene by conversion from $\mathrm{C} 4 \mathrm{~A}$ to $\mathrm{C} 4 \mathrm{~B}$.

To characterize the C4AQ0 nonexpressed alleles in the remaining 11 individuals, we selected 18 oligonucleotide primers from the published genomic $\mathrm{C} 4 \mathrm{~A}$ sequence that allow the amplification of all C4 exons as shown in Fig. 1. The nine amplified genomic fragments range in size from 0.8 to $1.7 \mathrm{~kb}$, and contain three to six exons each (Table I). The resulting PCR products from a normal individual without the $\mathrm{C} 4$ null allele $(A)$ and an individual with a nonexpressed $C 4 \mathrm{~A}$ gene on one haplotype and a $\mathrm{C} 4 \mathrm{~A}$ deletion on the other haplotype $(B)$ are

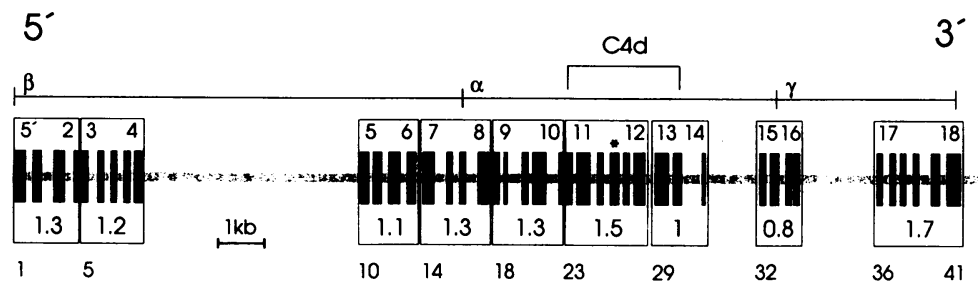

(a)

(b) cific C4d region; $(b)$ location of PCR primer pairs; $(c)$ sizes of amplified fragments (in kilobases); $(d)$ numbers of the first exon of each amplified fragment.

(d)

Figure 1. Map of the $\mathrm{C} 4$ gene structure and location of PCR primers for exon amplification. (a) $\mathrm{C} 4$ protein subunit organization and location of the isotype-speThe asterisk indicates the location of the isotype-specific Chido $-/+4$ sequence in exon 26 . 


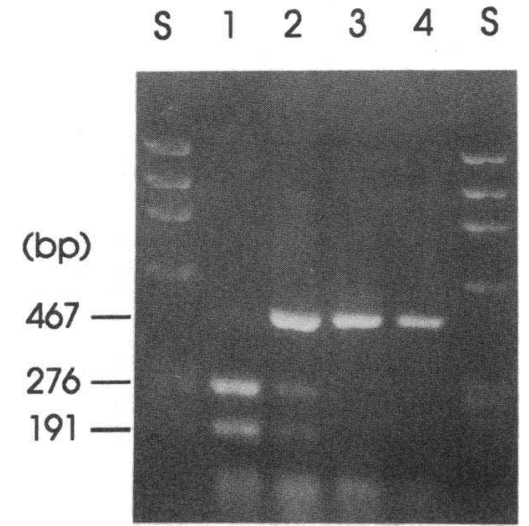

Figure 2. NlaIV restriction fragment analysis of PCR-amplified DNA for the identification of the $\mathrm{C} 4$ genotype. The amplified 926-bp fragment covers the $\mathrm{C} 4$ isotype-specific sequences: after NlaIV digestion, a single 467-bp fragment is characteristic of the C4B isotype (Chido +4) and the 276- and 191-bp fragments are characteristic of the C4A isotype (Chido -4). The genotypes studied are as follows: lane 1, C4A genotype control $\mathrm{C} 4 \mathrm{~A} 3,2$ $\mathrm{BQ} 0, \mathrm{Q} 0$ with C4B to C4A gene conversion; lane 2, C4AQ0,Q0 B1,2 with one nonexpressed $\mathrm{C} 4 \mathrm{~A}$ gene and one $\mathrm{C} 4 \mathrm{~A}$ gene deletion; lane 3, $C 4 A Q 0, Q 0 B 2,1$ with one $C 4 A$ gene deletion and a gene conversion from C4A to C4B; lane 4, C4B genotype control C4AQ0,Q0 B1,1 with both C4A genes deleted; $S, \Phi \times 174$-HaelII-digested DNA as size marker.

represented in Fig. 3. Since both the C4A and C4B genes are amplified simultaneously in this experiment, any structural deviation in the defective gene should be visible as an additional fragment in individual B. No obvious difference in the size of the amplified exons can be seen, providing further evidence that the nondeleted C4A null gene is structurally intact.

The analysis of the nine amplified fragments by SSCP gel electrophoresis did not reveal any differences between the DNA from three control individuals and three unrelated individuals with nonexpressed C4A null alleles for primers $5^{\prime} / 2$, $3 / 4,5 / 6,7 / 8,9 / 10,15 / 16$, and $17 / 18$ as shown in Fig. $4 A$ for primers $15 / 16$. Characteristic SSCP and heteroduplex polymorphisms were obtained using primers $11 / 12$ that amplify the central portion of the C4d region, since these exons $25-28$ contain well-defined isotype-specific sequence differences coding for the Rodgers (C4A) and Chido (C4B) blood groups of the $C 4$ molecule (26) (not shown; manuscript in preparation).
Finally, using primers $13 / 14$ and restriction enzyme digestion with Hinf $\mathrm{I}$, we detected an additional fragment of $\sim 250$ bp in two of the three samples with nonexpressed C4A null alleles (Fig. $4 B$, lanes 3 and 4 ), which was not found in any of the control individuals. Therefore, this PCR fragment covering exons 29-31 was selected for detailed DNA sequence analysis.

Genomic DNA sequence analysis of this fragment using PCR primer 13 as sequencing primer revealed a mixed $\mathrm{C} 4 \mathrm{~A} /$ C4B sequence containing a 2-bp shift in the reading frame (not shown). Since the origin of this possible insertion was not visible with this sequencing reaction, it had to be very close to the sequencing primer annealing site. Therefore, we synthesized primer $13 \mathrm{~N}$, which anneals to the opposite coding strand and extends the sequencing reaction into the direction of the possible insertion site. Thus we detected a 2-bp insertion at nucleotide position 5877 (numbers according to reference 5) in exon 29 as demonstrated in Fig. 5. The sequence of the noncoding strand of a control individual typed C4A3B $1(A)$ is shown in comparison to that of an individual with the defective $\mathrm{C} 4 \mathrm{~A}$ gene and normal $\mathrm{C} 4 \mathrm{~B} 1$ alleles $(B)$. A mixed DNA sequence pattern can be observed beginning at the $C$ in position 5877 and extending upstream, resulting in a two-nucleotide reading frame shift. This observation could be confirmed after isotypespecific amplification with the primer A-down, which only anneals to the C4A-specific DNA sequence coding for the $\mathrm{Ch}-4$ sequence in exon 26 (see Fig. 1), together with primer 14, and by sequencing both strands in this region with primers 13 and $13 \mathrm{~N}$ (not shown).

The genomic DNA sequence of exon 29 , intron 29 , and the beginning of exon 30 , as well as the translated amino acid sequence is illustrated in Fig. 6. In the mutationally altered C4A sequence, the last correctly translated codon would be amino acid position 1214. Beginning with position 1215, a sequence of 68 amino acid residues follows to the end of exon 29, which is completely different from the normal C4 sequence. Assuming a regular splicing of the relatively short intron 29 , two more codons are found in exon 30 . The next triplet in this sequence represents the stop codon TGA ( $Z$ in Fig. 6 ), which terminates the translation of this C4A transcript.

Our initial results using SSCP analysis (Fig. 4) provided

\section{$S \frac{5^{\prime} / 2}{A B} \frac{3 / 4}{A B} \frac{5 / 6}{A B} \frac{7 / 8}{A B} \frac{9 / 10}{A B} S \frac{11 / 12}{A B} \frac{13 / 14}{A B} \frac{15 / 16}{A B} \frac{17 / 18}{A B}$}

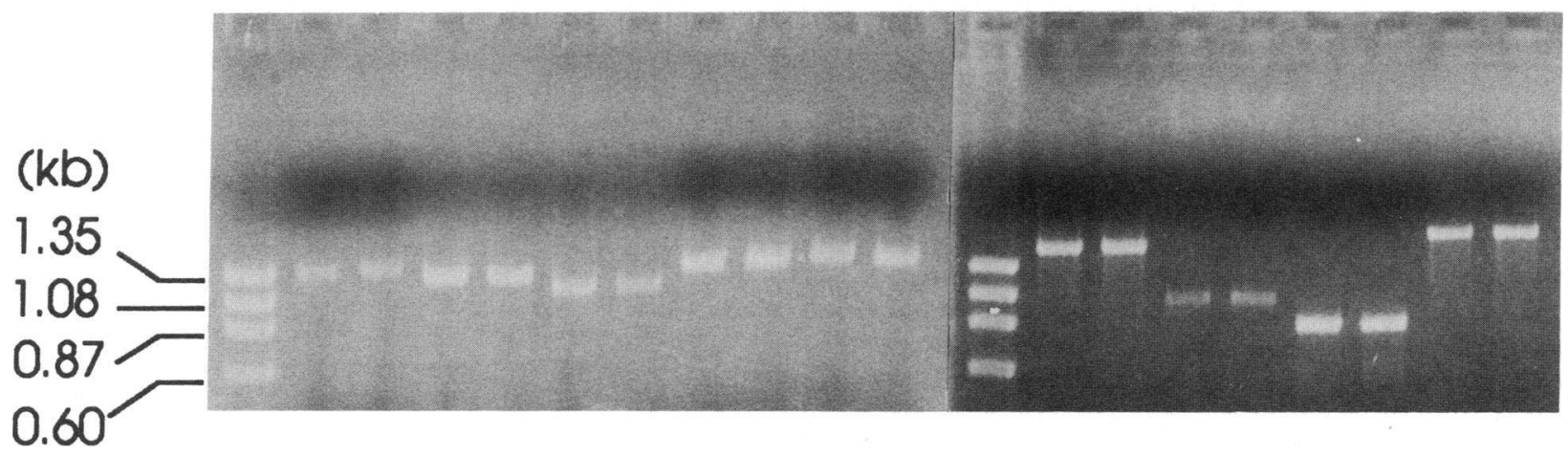

Figure 3. Exon-specific PCR amplification of DNA from one control individual ( $A$, C4A3B1) and one individual with a nonexpressed C4A gene $(B, \mathrm{C} 4 \mathrm{AQ} 0 \mathrm{~B} 1$ ). The respective primer pairs for each fragment (see Fig. 1 and Table I) are indicated above; $S, \Phi \mathrm{X} 174-\mathrm{HaeIII}-\mathrm{digested}$ DNA as size marker. 

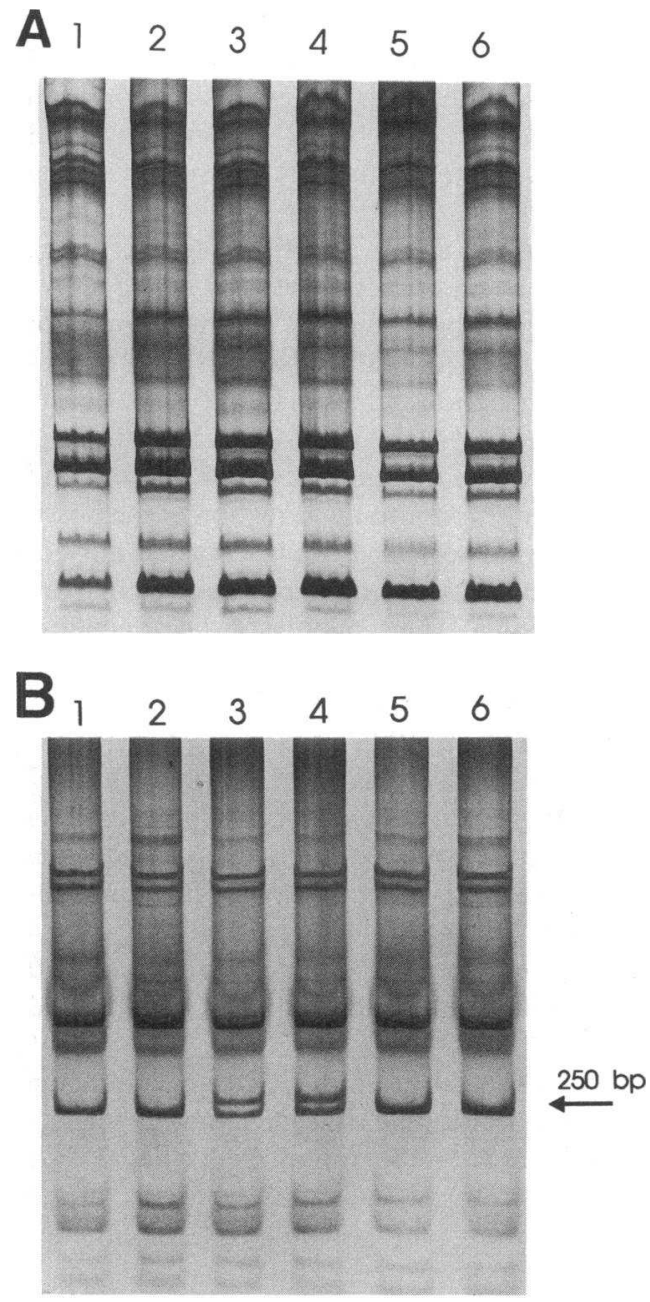

Figure 4. PCR-SSCP and heteroduplex analysis of selected exons of the $\mathrm{C} 4$ genes for the detection of sequence variations. $(A) 0.8-\mathrm{kb}$ fragment with exons 32-35 amplified with primers $15 / 16$ and digested with PvulI. Electrophoresis was carried out in a 14-cm-long $0.5 \times \mathrm{MDE}$ gel for $2.5 \mathrm{~h}$ at $150 \mathrm{~V}$. (B) 1-kb fragment with exons 2931 amplified with primers $13 / 14$ and digested with Hinf I. Electrophoresis was carried out in a 14-cm-long $5 \%$ polyacrylamide gel for $2.5 \mathrm{~h}$ at $150 \mathrm{~V}$. The samples studied are as follows: lane 1, C4A genotype control $\mathrm{C} 4 \mathrm{~A} 3,2 \mathrm{BQ}, \mathrm{Q} 0$ with $\mathrm{C} 4 \mathrm{~B}$ to $\mathrm{C} 4 \mathrm{~A}$ gene conversion; lane 2, C4 genotype control C4A3B1; lane 3, C4AQ0,Q0 B1, 1 with one defective C4A gene and one C4A gene deletion (with a 2-bp insertion in exon 29); lane 4, C4AQ0,Q0 B1,2 with one defective C4A gene and one C4A gene deletion (with a 2-bp insertion in exon 29); lane 5, C4AQ0,Q0 B1,2 with one defective C4A gene and one C4A gene deletion (without a 2-bp insertion in exon 29); lane 6, C4B genotype control C4AQ0,Q0 B1,1 with both C4A genes deleted.

evidence that the mutation leading to nonexpression of the defective C4A gene is not present in all haplotypes with $\mathrm{C} 4 \mathrm{~A}$ null genes. The individual in lane 5 of (Fig. $4 \mathrm{~B}$ ) does not exhibit the additional 250-bp fragment observed in the two other C4A-deficient individuals in lanes 3 and 4 . Therefore, we studied a total of 11 individuals carrying haplotypes with nonexpressed C4A null alleles using amplification of exons 29-31 and subsequent SSCP electrophoresis for the presence of this mutation. The results are summarized in Table II. Only one
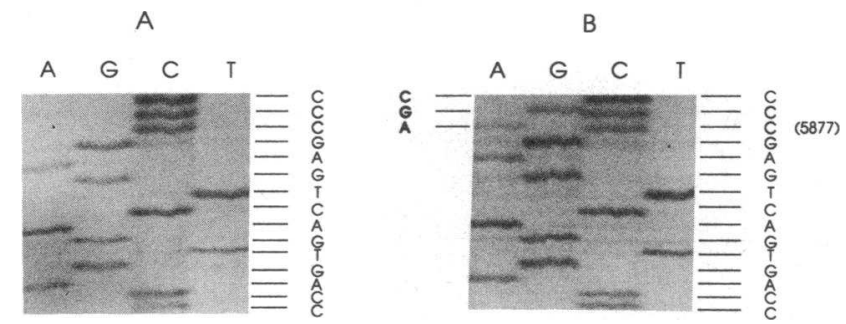

Figure 5. DNA sequence of $\mathrm{C} 4$ exon 29 (noncoding strand) obtained by $\mathrm{PCR}$ amplification with primers $13 / 13 \mathrm{~N}$ and sequencing primer 13N. (A) Control sample C4A3B1; (B) C4AQ0,Q0 B1,1 with one defective $C 4 \mathrm{~A}$ gene and one $\mathrm{C} 4 \mathrm{~A}$ gene deletion: the normal sequence is shown at the right side and the mutationally altered sequence with the 2-bp insertion is shown at the left side of $B$ ( 5877 is the nucleotide position of the insertion).

haplotype was identified that did not carry the 2-bp insertion. 8 of the $10 \mathrm{C} 4 \mathrm{~A}$ genes with the insertion were linked to HLAB60, and, with a single exception, to HLA-DR6. The two other haplotypes had HLA-B8 and either DR3 or DR6. The adjacent $\mathrm{C} 4 \mathrm{~B}$ genes of these haplotypes expressed either the B1 or the B2 allotype. All C4B genes were short, i.e., without the $6.5-\mathrm{kb}$ intron, as demonstrated by the detection of a 5.4-kb TaqI restriction fragment. The haplotype not carrying the mutation was HLA-B35, DR3.

(exon 29)

5867 CTG TAC TGG GGC TCA GTC ACT GGT TCT CAG AGC .. (normal C4 $\begin{array}{llllllllllllll}1210 & \text { L } & \text { Y } & \text { W } & G & S & V & \text { T } & G & S & Q & S & \ldots & \text { sequence) }\end{array}$

2 bp insertion: * *

5867 CTG TAC TGG GGC TCT CAG TCA CTG GTT CTC AGA GCA ATG CCG

$\begin{array}{lllllllllllllll}1210 & \text { L } & \text { Y } & \text { W } & G & \text { S } & \mathbf{Q} & \mathbf{B} & \text { I } & \text { V } & \text { I } & \mathbf{R} & \mathbf{A} & \mathbf{A} & \mathbf{P}\end{array}$

TGT CGC CCA CCC CGG CTC CTC GCA ACC CAT CCG ACC CCA TGC $\begin{array}{llllllllllllll}\mathbf{C} & \mathbf{R} & \mathbf{P} & \mathbf{P} & \mathbf{R} & \mathbf{L} & \mathbf{L} & \mathbf{A} & \mathbf{T} & \mathbf{A} & \mathbf{P} & \mathbf{T} & \mathbf{P} & \mathbf{C}\end{array}$

CCC AGG CCC CAG CCC TGT GGA TTG AAA CCA CAG CCT ACG CCC $\begin{array}{llllllllllllll}\mathbf{P} & \mathbf{R} & \mathbf{P} & \mathbf{Q} & \mathbf{P} & \mathbf{C} & \mathbf{G} & \mathbf{I} & \mathbf{K} & \mathbf{P} & \mathbf{Q} & \mathbf{P} & \mathbf{T} & \mathbf{P}\end{array}$

TGC TGC ACC TCC TGC TTC ACG AGg GCA Aag CAg AGA TGG CAG $\begin{array}{llllllllllllll}C & C & \mathbf{T} & \mathbf{S} & \mathbf{C} & \mathbf{F} & \mathbf{T} & \mathbf{R} & \mathbf{A} & \mathbf{K} & \mathbf{Q} & \mathbf{R} & \mathbf{W} & \mathbf{Q}\end{array}$

ACC AGG CTG CGG CCT GGC TCA CCC GTC AGG GCA GCT TCC AAG $\begin{array}{llllllllllllll}\mathbf{T} & \mathbf{R} & \mathbf{I} & \mathbf{R} & \mathbf{P} & \mathbf{G} & \mathbf{8} & \mathbf{P} & \mathbf{V} & \mathbf{R} & \mathbf{A} & \mathbf{A} & \mathbf{8} & \mathbf{K}\end{array}$

GGG GAT TCC GCA GTA CCC AA OTAGGGGCGTCCCCGGGCTCTGGGG G $\quad D \quad s \quad A \quad v \quad P \quad x$ (intron $29 \ldots \ldots \ldots \ldots$

9071 GGGTGGTAGTCCTCAGACCAAGGGCTTGCTTGAGTCCTGGCTCAACCTCCCTMO

(exon 30)

9126 G ACA CGG TGA ...

T R I (=stop)

Figure 6. DNA and translated amino acid sequences of exon 29 around the insertion site and location of the stop codon in exon 30 (underlined; $Z$ ) in comparison to the respective sequence of exon 29 of a normal C4 gene; the changed amino acid sequence after the insertion site is printed in boldface. The GT/AG splice signal of intron 29 is also printed in boldface. The nucleotide and amino acid positions are indicated at the left, and the inserted nucleotides are marked by asterisks. 
Table II. SSCP Analysis of C4A Gene Exon 29 of HLA Haplotypes with Silent C4A Null Genes

\begin{tabular}{|c|c|c|c|c|c|c|c|c|c|c|c|}
\hline \multirow{2}{*}{\multicolumn{4}{|c|}{ HLA- }} & \multirow{2}{*}{\multicolumn{2}{|c|}{ Allotypes }} & \multicolumn{4}{|c|}{ Taq I fragment } & \multirow{3}{*}{$\begin{array}{c}\text { Ex. } 29 \\
\text { Ins. }\end{array}$} & \multirow[b]{3}{*}{ No. } \\
\hline & & & & & & & CYP & & CYP & & \\
\hline \multirow[t]{2}{*}{ A } & C & B & DR & C4A & C4B & C4A & $21 \mathrm{~A}$ & C4B & $21 \mathrm{~B}$ & & \\
\hline & & & & \multicolumn{8}{|c|}{$(k b)$} \\
\hline $2(32)$ & w3 & 60 & 6 & $\mathrm{Q} 0$ & 1 & 7.0 & 3.2 & 5.4 & 3.7 & + & (3) \\
\hline $2(24)$ & w3 & 60 & 6 & Q0 & 2 & 7.0 & 3.2 & 5.4 & 3.7 & + & (4) \\
\hline 2 & w3 & 60 & 3 & Q0 & 2 & 7.0 & 3.2 & 5.4 & 3.7 & + & (1) \\
\hline 1 & w7 & 8 & 6 & Q0 & 2 & 7.0 & 3.2 & 5.4 & 3.7 & + & (1) \\
\hline 2 & & 8 & 3 & Q0 & 1 & 7.0 & 3.2 & 5.4 & 3.7 & + & (1) \\
\hline 19 & & 35 & 3 & Q0 & 2 & 7.0 & 3.2 & 5.4 & 3.7 & - & (1) \\
\hline
\end{tabular}

\section{Discussion}

The strategy of exon-specific PCR amplification using oligonucleotide primers from flanking intron sequences, screening for possible mutation sites by SSCP analysis, and subsequent direct genomic sequencing of specific target fragments represents a rapid and powerful approach for the detection of sequence variation in well-defined genetic systems. Genomic cloning in lambda or cosmid vectors, as well as extensive DNA sequencing, is avoided, and a large number of samples can be studied simultaneously. However, the analysis of SSCP and heteroduplex DNA fragments may not detect all existing mutations. The resolution depends strongly on the sizes of the fragments to be analyzed, the composition of the gel system, and the electrophoretic conditions. According to methodological studies regarding SSCP and heteroduplex analysis, the possibility of detecting a point mutation decreases with increasing fragment size $(21,27)$. The insertion detected in the nonexpressed $\mathrm{C} 4 \mathrm{~A}$ gene represents a major conformational alteration of the respective fragment that facilitated its detection.

From previous studies it was known that only a proportion of $\mathrm{C} 4 \mathrm{~A}$ null alleles are due to gene deletions. The majority of these $\mathrm{C} 4 \mathrm{~A}$ gene deletions were found among the Caucasoid population within the extended haplotype HLA-A1-Cw7-B8C2C-B fS-C4AQ0-B1-DR3 $(10,14)$. The molecular basis of $\mathrm{C} 4 \mathrm{~A}$ null alleles not due to gene deletions remained unclear. It could be established, however, that these genes are dysfunctional, since they carry C4A-specific DNA sequences without expressing any $C 4 A$ gene product. Conversion of the $C 4 A$ gene to $C 4 B$ as described for the gene conversion from $C 4 B$ to $C 4 A$ in the HLA-B44-C4A3-BQ0 haplotype was not detected in a previous study (15). Only a single HLA haplotype has been described with a conversion from C4A to C4B in the HLA haplotype B13-C4AQ0-B6,1-DR7 (28). In this study, we identified one individual with conversion from $\mathrm{C} 4 \mathrm{~A}$ to $\mathrm{C} 4 \mathrm{~B}$, possibly leading to homoduplication and -expression of the C4B2 allotype on the haplotype HLA-A3-Cw4-B35-C4AQ0-C4B2DR4 (Fig. 2, Table II).

The observed 2-bp insertion in exon 29 of the defective C4A genes is in linkage with HLA-B60 for 8 of the 10 haplotypes studied. Of these, seven also have the HLA-DR6 allele. The two remaining haplotypes have the HLA-B8 allele, one with DR3 and one with DR6. All haplotypes have a short C4B gene as indicated by the presence of a 5.4-kb TaqI fragment, but show a variation regarding the $C 4 B$ allotype, which may be either B1 or B2. Thus it is very likely that all these haplotypes might have arisen from a single mutational event in an ancestral HLA-B60, DR6 haplotype. Since C4B1 and B2 are found in almost equal numbers in this study (four and six, respectively), it might be speculated that the C4B allotypic variation was introduced shortly after the mutational event, either by an independent mutation changing the amino acid sequence of the adjacent $C 4 B$ gene or by a recombination between the defective $\mathrm{C} 4 \mathrm{~A}$ gene and the $\mathrm{C} 4 \mathrm{~B}$ gene. The sequence differences explaining the $C 4 B 1 / B 2$ variation resulting in a net charge difference of the gene product with $\mathrm{C} 4 \mathrm{~B} 1$ being more basic than C4B2 have not yet been defined. The sequence differences described so far originate from the $\mathrm{C} 4 \mathrm{~d}$ region (exons 23-30), but do not account for the observed electrophoretic migration difference between the B1 and B2 variants $(29,30)$. Therefore, subtypes of B2 may exist that have arisen from independent mutational events resulting in a net charge of the protein characteristic for the B2 allotype.

Insertional mutagenesis as a cause of genetic defects has already been observed in a number of genes (e.g., in alpha-2antiplasmin deficiency [31], beta-thalassemia [32], and cystic fibrosis [33]). A recent survey on this type of mutational event with insertions smaller than 10 bp by Cooper and Krawczak (34) showed that two mechanisms seem to be involved: $(a)$ slipped mispairing mediated by direct repeats or runs of identical bases, and ( $b$ ) misincorporation of bases due to the formation of secondary structure intermediates induced by palindromic sequences or symmetric elements. The insertion detected in the C4A pseudogenes belongs to the first category, since the original sequence of the insertion site CTC is changed to CTCTC by addition of a CT or a TC dinucleotide (Figs. 5 and 6). A similar insertion was observed in beta-thalassemia, where a TGTG sequence (at residue 148 - Leu ) was changed to TGTGTG by insertion of a TG dinucleotide (32). No functional gene product can be expected from the C4A mutationally altered sequence, since the reading frame shift causes a complete change of the amino acid sequence in the last third of the $\alpha$ chain, followed by a termination codon at the beginning of exon 30 (Fig. 6). The resulting truncated $C 4$ translation product is probably not stable and therefore degraded rapidly intracellularly. Thus the 2-bp insertion is sufficient to explain the nonexpression of these defective C4A genes. However, we cannot completely exclude the possibility that other mutations are also present in these genes that were not detected by SSCP analysis. Regarding the single haplotype with HLA-B35, which 
does not have the described 2-bp insertion (Table II), investigations are currently being carried out to identify the unknown genetic defect also causing C4A nonexpression.

Similar observations regarding the heterogeneity of the genetic basis of deficiency as well as the finding of strong MHC haplotype linkage have been described recently for complement $\mathrm{C} 2$ deficiency (35). The authors identified a 28-bp deletion spanning the splice junction of exon/intron 6 of the $\mathrm{C} 2$ gene as the cause for deficiency. This mutation is linked to the haplotype HLA-A25-B18-C2Q0-B fS-C4A4-C4B2-DR2, whereas $\mathrm{C} 2$ deficiency outside this extended haplotype has a different and as yet unknown genetic basis. Our findings demonstrate that a majority of the nonexpressed $\mathrm{C} 4 \mathrm{~A}$ genes among the Caucasian population have arisen from a single insertional mutation linked to the HLA haplotype B60-DR6, which was then spread by recombination to haplotypes with different HLA-B and/or DR alleles. However, this mutation was not found in all haplotypes with a defective C4A gene studied, providing evidence for heterogeneity in the genetic basis of $\mathrm{C} 4 \mathrm{~A}$ deficiency.

\section{Acknowledgments}

This study was supported by a grant from the Deutsche Forschungsgemeinschaft (DFG Schn 284/3-1).

\section{References}

1. Carroll, M. C., R. D. Campbell, D. R. Bentley, and R. R. Porter. 1984. A molecular map of the human major histocompatibility complex class III region linking complement genes C4, C2 and factor B. Nature (Lond.). 307:237-241.

2. Carroll, M. C., R. D. Campbell, and R. R. Porter. 1985. Mapping of steroid 21-hydroxylase genes adjacent to the complement component $\mathrm{C} 4$ genes in HLA the major histocompatibility complex in man. Proc. Natl. Acad. Sci. USA. 82:521-525.

3. White, P. C., D. Grossberger, B. J. Onufer, D. D. Chaplin, M. I. New, B. Dupont, and J. L. Strominger. 1985. Two genes encoding steroid 21-hydroxylase are located near the genes encoding the fourth component of complement in man. Proc. Natl. Acad. Sci. USA. 82:1089-1093.

4. Prentice, H. L., P. M. Schneider, and J. L. Strominger. 1986. C4B gene polymorphism detected in a human cosmid clone. Immunogenetics. 23:274-276.

5. Yu, C. Y. 1991. The complete exon-intron structure of a human complement component C4A gene: DNA sequences, polymorphism, and linkage to the 21-hydroxylase gene. J. Immunol. 146:1057-1066.

6. Mauff, G., M. Brenden, M. Braun-Stilwell, G. Doxiadis, C. Giles, G. Hauptmann, C. Rittner, P. M. Schneider, B. Stradmann-Bellinghausen, and B. Uring-Lambert. 1990. C4 reference typing report. Complement Inflammation. 7:193-212.

7. Rittner, C., and P. M. Schneider. 1988. Genetics and polymorphism of the complement components. In The Complement System. K. Rother and G. O. Till, editors. Springer-Verlag, Berlin. 80-135.

8. Hauptmann, G., G. Tappeiner, and J. A. Schifferli. 1988. Inherited deficiency of the fourth component of human complement. Immunodeficiency Rev. $1: 3-22$.

9. Fielder, A. H. L., M. J. Walport, J. R. Batchelor, R. I. Rynes, C. M. Black, I. A. Dodi, and G. R. V. Hughes. 1983. Family study of the major histocompatibility complex in patients with systemic lupus erythematosus: importance of null alleles of C4A and C4B in determining disease susceptibility. Br. Med. J. 286:425-428.

10. Schneider, P. M., K. Hartung, S. A. Seuchter, E. Albert, M. P. Baur, R. Coldewey, J. R. Kalden, H. J. Lakomek, H. H. Peter, C. Rittner, D. Schendel, and H. R. G. Deicher. 1992. Association of MHC class I, II, and III genes with systemic lupus erythematosus: results of a German collaborative study. In HLA 1991. Vol. 2. K. Tsuji, M. Aizawa, and T. Sazazuki, editors. Oxford University Press, Oxford, UK. 525-528.

11. Rittner, C., E. M. M. Meier, B. Stradmann, C. M. Giles, R. Köchling, E.
Mollenhauer, and H. W. Kreth. 1984. Partial C4 deficiency in subacute sclerosing panencephalitis. Immunogenetics. 20:407-415.

12. Manns, M. P., A. Bremm, P. M. Schneider, A. Notghi, G. Gerken, M. Prager-Eberle, B. Stradmann-Bellinghausen, K.-H. Meyer zum Büschenfelde, and C. Rittner. 1991. HLA-DRw8 and complement C4 deficiency as risk factors in primary biliary cirrhosis. Gastroenterology. 101:1367-1373.

13. Carroll, M. C., A. Palsdottir, K. T. Belt, and R. R. Porter. 1985. Deletion of complement $\mathrm{C} 4$ and steroid 21-hydroxylase genes in the HLA class III region. EMBO (Eur. Mol. Biol. Organ.) J. 4:2547-2552.

14. Schneider, P. M., M. C. Carroll, C. A. Alper, C. Rittner, A. S. Whitehead, E. J. Yunis, and H. R. Colten. 1986. Polymorphism of the human complement C4 and steroid 21-hydroxylase genes. Restriction fragment length polymorphisms revealing structural deletions, homoduplications and size variants. $J$. Clin. Invest. 78:650-657.

15. Braun, L., P. M. Schneider, C. M. Giles, J. Bertrams, and C. Rittner. 1990. Null alleles of human complement C4. Evidence for pseudogenes at the C4A locus and for gene conversion at the C4B locus. J. Exp. Med. 171:129-140.

16. Hartung, K., E. Albert, M. P. Baur, F. Coldewey, J. R. Kalden, H. J. Lakomek, H. H. Peter, D. Schendel, P. M. Schneider, S. Seuchter, W. Stangel, and $H$. Deicher. 1992. MHC haplotypes and complement $C 4$ alleles in systemic lupus erythematosus. Results of a multicenter study. J. Clin. Invest. 90:13461351.

17. Terasaki, P. I., and J. D. McClelland. 1964. Microdroplet assay of human serum cytotoxins. Nature (Lond.). 204:998-1000.

18. Awdeh, Z. L., and C. A. Alper. 1980. Inherited structural polymorphism of the fourth component of human complement. Proc. Natl. Acad. Sci. USA. 77:3576-3580.

19. Roos, M. H., E. Mollenhauer, P. Démant, and C. Rittner. 1982. A molecular basis for the two locus model of human complement component C4. Nature (Lond.). 298:854-856.

20. Don, R. H., P. T. Cox, B. J. Wainright, K. Baker, and J. S. Mattick. 1991. 'Touchdown' PCR to circumvent spurious priming during gene amplification. Nucleic Acids Res. 19:4008.

21. Hayashi, K. 1991. PCR-SSCP: a simple and sensitive method for detection of mutations in genomic DNA. PCR Methods and Applications. 1:34-38.

22. Spinardi, L., R. Mazars, and C. Theillet. 1991. Protocol for an improved detection of point mutations by SSCP. Nucleic Acids Res. 19:4009.

23. Sammons, D. W., L. D. Adams, and E. E. Nishizawe. 1981. Ultrasensitive silver-based color staining of polypeptides in polyacrylamide gels. Electrophoresis. 2:135-141.

24. Belt, K. T., M. C. Carroll, and R. R. Porter. 1984. The structural basis of the multiple forms of human complement component C4. Cell. 36:907-914.

25. Yu, C. Y., and R. D. Campbell. 1987. Definitive RFLPs to distinguish between the human complement C4A/C4B isotypes and the major Rodgers/ Chido determinants: application to the study of $\mathrm{C} 4$ null alleles. Immunogenetics. 25:383-390.

26. Giles, C. M. 1990. C4 Rodgers and Chido typing. Complement Inflammation. 7:213-217.

27. Soto, D., and S. Sukumar. 1992. Improved detection of mutations in the p53 gene in human tumors as single-stranded conformation polymorphisms and double-stranded heteroduplex DNA. PCR Methods and Applications. 2:96-98.

28. Robson, T., C. M. Giles, and R. N. S. Heard. 1989. An epitope on C4 $\beta$ light (L) chains detected by human anti-Rg: its relationship with $\beta$ chain polymorphism and MHC associations. Immunogenetics. 30:344-349.

29. Belt, K. T., C. Y. Yu, M. C. Carroll, and R. R. Porter. 1985. Polymorphism of human complement component C4. Immunogenetics. 21:173-180.

30. Yu, C. Y., K. T. Belt, C. M. Giles, R. D. Campbell, and R. R. Porter. 1986. Structural basis of the polymorphism of human complement components C4A and C4B: gene size, reactivity and antigenicity. EMBO (Eur. Mol. Biol. Organ.) J. 5:2873-2881.

31. Holmes, W. E., H. R. Lijnen, L. Nelles, C. Kluft, H. K. Nienwenhuis, D. C. Rijken, and D. Collen. 1987. Alpha 2-antiplasmin Enschede: alanine insertion and abolition of plasmin inhibitory activity. Science (Wash. DC). 238:209211.

32. Chan, V., T. K. Chan, Y. W. Kan, and D. Todd. 1988. A novel beta-thalassaemia frameshift mutation (codon 14/15), detectable by direct visualization of abnormal restriction fragment in amplified genomic DNA. Blood. 72:14201423.

33. White, M. B., J. Amos, J. M. C. Hsu, B. Gerrard, P. Firm, and M. Dean 1990. A frame-shift mutation in the cystic fibrosis gene. Nature (Lond.). 344:665-667.

34. Cooper, D. N., and M. Krawczak. 1991. Mechanisms of insertional mutagenesis in human genes causing genetic deficiency. Hum. Genet. 87:409-415.

35. Johnson, C. A., P. Densen, R. K. Hurford, H. R. Colten, and R. A. Wetsel 1992. Type I human complement C2 deficiency. J. Biol. Chem. 267:9347-9353. 